\title{
HOW DO MARKET CHARACTERISTICS INFLUENCE BRAND COUNTRY OF ORIGIN EFFECTS?
}

Shuang Yang, University of Texas at El Paso, USA

Fernando Jimenez, University of Texas at El Paso, USA

John Hadjimarcou, University of Texas at El Paso, USA

Gary Frankwick, University of Texas at El Paso, USA

\begin{abstract}
ABSTIRACT
Given that brands are important for consumers' recognition of country of origin (COO), recent investigations have focused on the influence of county of brand (COB) on consumers' purchase decisions (Martin Martin and Cerviño 2011). Based on information diagnosticity theory, we propose that the effect of $\mathrm{COB}$ on product evaluations depends on the market characteristics of a given product category.

In the present study, market characteristics refer to the number and heterogeneity of COBs in a given market. The former refers to the perceived number of countries associated with brands, while the latter refers to the variance of perceived product quality among the identified COBs. Wo posit that in a market for a product category with a large number of COBs, consumers will find $\mathrm{COB}$ to be less diagnostic, and $\mathrm{COB}$ will play a lesser role in product evaluations. The reason is that the distinctiveness of the information provided by a $\mathrm{COB}$ will be diluied because many countries will be perceived as being able to deliver a certain product. In addition, we argue that when consumers perceive a high level of heterogeneity of $\mathrm{COBs}$, $\mathrm{COB}$ will be more diagnostic in product evaluations because heterogeneity of $\mathrm{COB}$ indicates the perccived quality asymmetry among COBs in the market. We discuss the potential implications of this research for theory and practice.
\end{abstract}

References available upon request 